\title{
Inappropriate prescribing in the hospitalized elderly patient: Defining the problem, evaluation tools, and possible solutions
}

This article was published in the following Dove Press journal:

Clinical Interventions in Aging

25 March 2010

Number of times this article has been viewed

\section{Robert L Page II' \\ Sunny A Linnebur ${ }^{2}$ \\ Lucinda L Bryant ${ }^{3}$ \\ J Mark Ruscin ${ }^{4}$}

'Associate Professor of Clinical Pharmacy and Physical Medicine, Clinical Specialist, Division of Cardiology and Heart Transplantation, ${ }^{2}$ Associate Professor of Clinical Pharmacy, Clinical Specialist, Center on the Aging, Schools of Pharmacy and Medicine, ${ }^{3}$ Assistant Professor of Community and Behavioral Health, Colorado School of Public Health, University of Colorado Denver, Aurora, CO, USA; ${ }^{4}$ Professor, Department of Pharmacy Practice, Southern Illinois University Edwardsville School of Pharmacy, Edwardsville, IL, USA
Correspondence: Robert Lee Page II Associate Professor of Clinical Pharmacy and Physical Medicine, Clinical Specialist, Cardiology, University of Colorado, School of Pharmacy and Medicine, C238-LI5, Academic Office I, I263I East 17th Ave, Room LI5-I4I5, PO Box 65II, Aurora, CO 80045, USA

Tel +l 3037242626

Fax +l 3037242627

Email robert.page@ucdenver.edu
Abstract: Potentially inappropriate medication (PIM) prescribing in older adults is quite prevalent and is associated with an increased risk for adverse drug events, morbidity, and utilization of health care resources. In the acute care setting, PIM prescribing can be even more problematic due to multiple physicians and specialists who may be prescribing for a single patient as well as difficulty with medication reconciliation at transitions and limitations imposed by hospital formularies. This article highlights critical issues surrounding PIM prescribing in the acute care setting such as risk factors, screening tools, and potential strategies to minimize this significant public health problem.

Keywords: inappropriate prescribing, aged, elderly, adverse drug events, adverse drug reactions, Beers' criteria, screening

The medication-use process is a complicated progression of steps traditionally consisting of prescribing, communicating orders, dispensing, administering, and monitoring. ${ }^{1}$ At each step, the potential for associated health risks exist; however, many preventable problems can occur at the initial prescribing stage. ${ }^{1}$ While no set definition has been established, inappropriate prescribing encompasses the use of medications that introduce a significant risk of an adverse drug event (ADE) when there exists evidence for an equally or more effective but lower-risk alternative therapy for treating the same medical condition. ${ }^{2}$ Additional situations also include over-use of medications at a higher frequency or for longer durations than clinically indicated, under-use of medically indicated medications based on ageist or irrational reasons, and use of multiple medications that have documented drug-drug interactions or drug-disease interactions. ${ }^{1,2}$

It is no surprise that inappropriate prescribing commonly occurs in adults aged 65 years or older, who have a higher prevalence of chronic disease, disability, and dependency than younger adults. ${ }^{3}$ While only $13 \%$ of Americans are aged 65 years or older, this group represents the largest per capita consumers of prescription medications., ${ }^{4,5}$ A recent survey of 3,500 community-dwelling adults found that over $29 \%$ take five or more prescription medications, $42 \%$ at least one or more over-the-counter medications, and $49 \%$ at least one or more dietary supplements. ${ }^{4}$ With increasing life expectancy, improved prescription drug coverage through the implementation of the Medicare Part D Prescription Drug Benefit Plan, and the emergence of over 50 new drugs per year into the United States (US) market, it seems likely that consumption of prescription drugs by older adults will continue to increase. Additionally, the continued development of life saving and lifestyle-saving medications, as well as direct to consumer marketing, 
seems to have created an excess dependence on medication therapy to solve everyday problems.

A number of studies have documented that potentially inappropriate medication (PIM) prescribing in older adults is common in the ambulatory setting, nursing homes, and the emergency department and that exposure to inappropriate medications is associated with increased morbidity, mortality, health care resource utilization, and ADEs. ${ }^{5}$ However, limited data exist regarding PIM prescribing in the acute care setting, although adults aged 65 years or older account for over 35\% of annual hospital admissions. ${ }^{6-10}$ Older adults are also at increased risk for hospital readmission. An analysis of fee for service Medicare beneficiaries found that $19.6 \%$ of patients who had been discharged from a hospital were rehospitalized within 30 days, and $34.0 \%$ were rehospitalized within 90 days. ${ }^{11}$ Of note, the hospital environment can be particularly perilous for older adults. Hospitalization has been associated with a higher incidence of adverse outcomes including functional decline, delirium, and falls as well as ADEs in this population. ${ }^{12,13}$ A meta-analysis of 39 studies found an inhospital incidence of ADEs of $6.7 \%$ and an incidence of fatal ADEs of $0.3 \%$, which may be slightly higher than what has been documented in the outpatient setting. ${ }^{14,15}$ Furthermore, older adults in the inpatient setting may be exposed to new and possibly unnecessary medications, multiple providers and specialists, and restrictive hospital formularies that require reconciliation with home medications; all of these can increase the risk for PIM prescribing. ${ }^{16,17}$

In order to address this public health concern in older adults, particularly within the hospital environment, it is crucial that clinicians have an understanding of potential risk factors for PIM prescribing, advantages and limitations of validated drug evaluation tools for identifying PIM prescribing, and possible strategic approaches to curtailing the problem.

\section{Risk factors for PIM prescribing}

No research has yet identified clear risk factors specific to PIM prescribing in the hospitalized older adult, but it may be possible to extrapolate from an evaluation of the root causes for ADEs to develop a potential list. Data in hospitalized patients suggest that advanced age ( $\geq 85$ years), polypharmacy, and number of comorbidities can contribute to an increased likelihood of ADEs. ${ }^{18-21}$

\section{Advanced age}

While complex issues surrounding frailty, social and emotional infrastructure, and economic status can influence inappropriate prescribing, the major impact of advanced age lies in the context of altered pharmacokinetics (drug absorption, distribution, metabolism and excretion), altered pharmacodynamics (physiological effects of the drug) and age-related changes in body composition and physiology. With advanced age, lean body mass and total body water decrease, with a relative increase in total body fat. Such changes lead to a decreased volume of distribution for hydrophilic, narrow therapeutic drugs such as lithium and digoxin for which unadjusted dosing can result in higher plasma concentrations and possible toxicity. Conversely, lipid-soluble drugs such as long-acting benzodiazepines have an increased volume of distribution, thereby delaying their immediate effects and resulting in potentially dangerous accumulation with continued use..$^{22}$

Advanced age is also associated with a reduction in hepatic mass and blood flow. Drugs such as beta-blockers, nitrates, and tricyclic antidepressants (TCAs) that exhibit significant hepatic first pass metabolism may have a higher bioavailability and faster onset, which will warrant initiation at lower doses with possible extended administration intervals. Cytochrome P450 oxidation also declines, increasing the risk for toxicity and possible drug - drug interactions for drugs that are substrates of these enzymes. ${ }^{23}$ With aging also come associated changes in renal structure and subsequent altered drug excretion. Drug dosages eliminated via the kidneys should be adjusted for compromised renal function. If serum albumin is decreased, the active unbound drug concentration will increase for highly protein-bound narrow therapeutic drugs such as phenytoin, theophylline, warfarin, and digoxin.

Finally, aging is also associated with changes in the endorgan responsiveness to drugs at receptor or post-receptor levels. There is decreased sensitivity to beta-receptors along with a possible decreased clinical response to beta-blockers and beta-agonists. The central nervous system becomes more vulnerable in the elderly to agents that affect brain function (eg, opioids, benzodiazepines, and psychotropic drugs). ${ }^{24}$

\section{Polypharmacy}

While treatment of multiple chronic diseases may justify the use of several drugs concomitantly, polypharmacy is associated with an increased risk for ADEs as well as drug-drug and drug-disease interactions. ${ }^{25}$ Goldberg and colleagues found that patients taking two drugs face a $13 \%$ risk of adverse drug-drug interactions, rising to $38 \%$ for four drugs and to $82 \%$ if seven or more drugs are given simultaneously. ${ }^{26}$ Duplicate prescribing within the same drug class is prevalent 
and frequently unrecognized..$^{25,26}$ ADEs are often treated with additional drugs, leading to prescribing cascades..$^{25}$ Polypharmacy can also augment the risk for medication nonadherence, which in turn can lead to suboptimal therapeutic effectiveness and poor clinical consequences.$^{27}$ If providers do not recognize the existence of medication nonadherence, they may increase the dose of the initial medication or add a second agent, increasing not only the cost of therapy but risk for an ADE. It is clear that the use of multiple medications is associated with an increase in the risk of ADEs. However, the use of specific medications, such as atypical and typical antipsychotics as well as benzodiazepines should be of particular concern as well, as these medications are associated with decreased patient functioning and increased morbidity and mortality. $3,28-30$

\section{Multiple comorbidities}

Among adults aged over 65 years, $84 \%$ present with two or more chronic conditions, compared with $35 \%$ of patients aged 45 to 65 years. ${ }^{31}$ Data have shown that having three or more comorbities can increase the risk for having a severe ADE by 2.9-12.6-fold. ${ }^{20}$ The pervasiveness of comorbidity is especially apparent in hospitals. In the hospital setting, $60 \%$ of inpatients had at least one comorbidity, and $37 \%$ had two or more. ${ }^{32}$ The leading comorbities were hypertension (29.4\%), chronic obstructive lung disease (COPD) (12.1\%), diabetes mellitus (11.8\%), fluid/electrolyte disorders (11.7\%), iron deficiency/anemia (7.9\%), and heart failure $(5.7 \%)$. With each comorbidity comes additional exposure to a larger number of medications as well as new prescribers and specialists. ${ }^{32}$ For example, a Medicare beneficiary with heart failure may see on average 15-23 different providers within a given year. ${ }^{33}$ In this scenario, communication between providers, flawless transitions of care, and the overall coordination of care are crucial, as failure in any of these steps could lead to duplication of medications, prescribing of unnecessary medications, and drug - drug interactions.

\section{Validated drug utilization review tools}

Appropriateness of prescribing can be assessed by process or outcome measures that are explicit (criterion-based) or implicit (judgment-based). ${ }^{5}$ Explicit indicators are usually developed from published reviews, expert opinions, and consensus techniques. These measures are usually drug or disease oriented and can be applied with little or no clinical judgment. Unfortunately, explicit criteria may not take into account all quality indicators of health care as defined by national guidelines for an individual patient and their preferences, nor do they address the burden of comorbid conditions. In implicit approaches, a clinician employs patient-specific information and published evidence to form judgments about appropriateness. The focus is placed on the patient rather than on drugs or diseases. Implicit approaches are potentially more sensitive and can account for patients' preferences, but they are time-consuming, depend on the users' knowledge and attitudes, and can have low reliability. While no ideal measure exists, the strengths and weaknesses of both approaches should be taken into account. Presently, four tools exist to evaluate PIM prescribing in older adults. ${ }^{5}$ The Beers' Criteria, Improved Prescribing in the Elderly Tool (IPET), and Screening Tool of Older Persons (STOPP) are explicit approaches, while the Medication Appropriateness Index (MAI) is an implicit model.

\section{The Beers' criteria}

In 1991, Beers and colleagues published the first set of explicit criteria for determining PIM use in nursing home residents. ${ }^{34}$ Based on consensus opinion from experts in geriatric medicine, long-term care, geriatric and psychogeriatric pharmacology and pharmacoepidemiology, they devised a list of 30 medications that should be avoided in nursing home residents regardless of diagnoses or dose and frequency of medication use. This list incorporated certain psychotropic medications, antihypertensives, oral hypoglycemic agents, nonsteroidal anti-inflammatory drugs (NSAIDs), and analgesic agents. In 1997, Beers published a revised and more comprehensive set of explicit criteria for potentially inappropriate drug use in ambulatory people aged 65 years or older. ${ }^{35}$ The revised criteria were designed to be applicable to all adults aged 65 years or older regardless of their place of residence (community or nursing home) or level of frailty. The criteria divided potentially inappropriate drugs into three categories: drugs that generally should be avoided in older adults; doses, frequencies, or durations of specific therapies that vary from those generally accepted as appropriate use in elderly persons; and drugs to be avoided in combination with a specific co-morbidity. Beers' criteria were again updated in $2003 .{ }^{36}$ The criteria specify PIMs both independent of diagnosis and condition (Table 1) and also by specific diagnosis and condition (Table 2). The new criteria included additions to the general list of inappropriate medications (eg, nitrofurantoin, doxazosin, and amiodarone). Fifteen medications and medication classes were removed from the 1997 list, eg, the use of beta-blockers (with exception of propranolol) in those with COPD, asthma, peripheral vascular disease and syncope or falls. The co-morbidity list in 
Table I 2002 Beers' criteria for potentially inappropriate medication use with a high severity rating in older adults: Independent of diagnosis or condition ${ }^{36}$

Drug
Amitriptyline, chlordiazepoxide-amitriptyline, perphenazine-amitriptyline
Amphetamines and anorexic drugs

Amiodarone

Antipsychotic medications: mesoridazine, thioridazine

Antihistamines and anticholinergic medications: chlorpheniramine, diphenhydramine, hydroxyzine, cyproheptadine, promethazine, tripelennamine, dexchlorpheniramine

Barbiturates: all barbiturates ${ }^{\mathrm{a}}$ except phenobarbital

Benzodiazepines (long-acting): chlordiazepoxide, chlordiazepoxideamitriptyline, clidinium-chlordiazepoxide, diazepam, quzepam, halazepam, chlorazepate

Benzodiazepines (short-acting): Lorazepam (doses exceeding $3 \mathrm{mg}$ ), oxazepam (doses exceeding $60 \mathrm{mg}$ ), alprazolam (doses exceeding $2 \mathrm{mg}$ ), temazpam (doses exceeding $15 \mathrm{mg}$ ), triazolam (doses exceeding $0.125 \mathrm{mg}$ )

Chlorpropramide

Desiccated thyroid

Disopyramide

Fluoxetine (daily use)

Flurazepam

Gastrointestinal antispasmodic drugs: dicyclomine, hyoscyamine, propantheline, clidinium-chlordiazepoxide

Guanethidine

Guanadrel

Indomethacin

Ketorolac

Meperidine

\section{Meprobamate}

Methyldopa and methyldopa-hydrochlorothiazide

Mineral oil

Muscle relaxants and antispasmodics: methocarbamol, carisoprodol, chlorzoxazone, metaxalone, cyclobenzaprine, oxybutynin (not XL formulation)

Nifedipine (short acting only)

Nitrofurantoin

NSAIDS (long-term use, longer half-life, non-COX selective): naproxen, oxaprozin, piroxicam

Orphenadrine

\section{Concern}

Exhibits strong anticholinergic and sedation properties.

Use is associated with dependence, hypertension, angina, and myocardial infarction;

Amphetamines other than methylphenidate and anorexic drugs can also cause CNS side effects.

Associated with QT interval prolongation, may provoke torsades de pointes, and lacks efficacy in the elderly.

Have CNS and extrapyramidal side effects.

Has potent anticholinergic properties and can cause sedation and confusion.

Are highly addictive and cause more adverse effects than most sedative or hypnotic drugs.

Exhibits long half-life, producing sedation and increasing incidence of falls and factures.

Increased sensitivity at higher doses.

Has a long half-life leading to possible prolonged hypoglycemia and can cause SIADH.

Has cardiac side effects concerns.

Has the most potent negative inotropic properties compared to other antiarrhythmic drugs and exhibits significant anticholinergic side effects.

Exhibits a long half-life and risk of producing excessive CNS stimulation, sleep disturbances, and agitation.

Exhibits long half-life, producing sedation and increasing incidence of falls and factures.

Have strong anticholinergic side effects and questionable efficacy.

Can cause orthostatic hypotension.

Can cause orthostatic hypotension.

Exhibits greatest CNS side effects compared to other NSAIDs.

Immediate and long-term use should be avoided as older adults have a higher incidence of asymptomatic Gl pathologic conditions.

May cause confusion and may lack effectiveness in doses commonly used.

Exhibits highly addictive and sedating properties.

May cause bradycardia and exacerbate depression.

Has potential for aspiration side effects.

Are poorly tolerated by elderly patients, exhibit anticholinergic side effects, sedation, and weakness; questionable effectiveness at doses tolerated by the elderly.

Causes hypotension and constipation.

Has potential for renal impairment.

Have the potential for produce Gl bleeding, renal failure, high blood pressure, and heart failure.

Causes more sedation and anticholinergic side effects than safer alternatives. 
Table I (Continued)

\begin{tabular}{ll}
\hline Drug & Concern \\
\hline Pentazocine & Causes more CNS side effects more commonly than other narcotic drugs. \\
Stimulant laxatives (long-term use only): bisacodyl, cascara sagrada & May exacerbate bowel dysfunction. \\
and neoloid & \\
Ticlopidine & No more effective than aspirin and may be considerably more toxic. \\
Trimethobenzamide & One of the lest effective antiemetic drugs and exhibits extrapyramidal \\
\end{tabular}

Abbreviations: COX, cyclooxygenase; CNS, central nervous system; GI, gastrointestinal; NSAIDs, nonsteroidal anti-inflammatory drugs; SIADH, syndrome of inappropriate antidiuretic hormone secretion; $\mathrm{XL}$, extended release; except when treating atrial arrhythmias.

Notes: ${ }^{a}$ Except when used to control seizures; ${ }^{b}$ Except in the presence of opiate analgesic use.

Table 22002 Beers' Criteria for potentially inappropriate medication use with a high severity rating in older adults: Considering diagnosis and condition. Modified from Reference 36

\begin{tabular}{lll}
\hline Disease or condition & Drug & Concern \\
\hline Anorexia and malnutrition & CNS stimulants: Dextroamphetamine, methylphenidate, & Concern due to appetite-suppressing effects. \\
methamphetamine, pemolin, and fluoxetine & Concern due to proarrhythmic effects and \\
Arrhythmias & TCAs (imipramine hydrochloride, doxepin hydrochloride, & ability to produce QT interval changes. \\
Bladder outflow obstruction & And amitriptyline hydrochloride) & May decrease urinary flow, leading to urinary \\
& muscle relaxants, oxybutynin, flavoxate, anticholinergics, & retention.
\end{tabular}

Blood clotting disorders or receiving anticoagulant therapy

\section{COPD}

Cognitive impairment

Depression

Gastric or duodenal ulcers

Heart failure

Hypertension

Insomnia

Parkinson disease

Seizures or epilepsy

Stress incontinence

Syncope or falls antidepressants, decongestants, and tolterodine

Aspirin, NSAIDs, dipyridamole, ticlopidine, and clopidogrel

Long-acting benzodiazepines: chlordiazepoxide, chlordiazepoxide-amitriptyline,clidinium-chlordiazepoxide, diazepam, quazepam, halazepam, and chlorazepate; $\beta$-blockers: propranolol

Barbiturates, anticholinergics, antispasmodics, and muscle Relaxants; CNS stimulants: dextroamphetamine, methylphenidate, methamphetamine, and pemolin

Long-term benzodiazepine use. Sympatholytic agents: methyldopa, reserpine, and guanethidine

NSAIDs and aspirin ( $\geq 325 \mathrm{mg}$ ) (coxibs excluded)

Disopyramide and high sodium content drugs (sodium and sodium salts [alginate bicarbonate, biphosphate, citrate, phosphate, salicylate, and sulfate])

Phenylpropanolamine hydrochloride ${ }^{a}$, pseudoephedrine; diet pills, and amphetamines

Decongestants, theophylline, methylphenidate, MAOls, and amphetamines

Metoclopramide, conventional antipsychotics, and tacrine

Clozapine, chlorpromazine, thioridazine, and thiothixene

$\alpha$-blockers (doxazosin, prazosin, and terazosin), anticholinergics, TCAs (imipramine, doxepin, and mitriptyline), and long-acting benzodiazepines

Short- to intermediate-acting benzodiazepine and TCAs (imipramine, doxepin, and amitriptyline)
May prolong clotting time and elevate INR values or inhibit platelet aggregation, resulting in an increased potential for bleeding.

CNS adverse effects. May induce respiratory depression. May exacerbate or cause respiratory depression.

Concern due to CNS-altering effects.

May produce or exacerbate depression.

May exacerbate existing ulcers or produce new/additional ulcers.

Negative inotropic effect. Potential to promote fluid retention and exacerbation of heart failure.

May produce elevation of blood pressure secondary to sympathomimetic activity.

Concern due to CNS stimulant effects.

Concern due to their antidopaminergic/ cholinergic effects.

May lower seizure thresholds.

May produce polyuria and worsening of incontinence.

May produce ataxia, impaired psychomotor function, syncope, and additional falls.

Abbreviations: CNS, central nervous system; COPD, chronic obstructive pulmonary disease; Gl, gastrointestinal; INR, international normalized ratio; MAOls, monoamine oxidase inhibitors; NSAIDs, nonsteroidal anti-inflammatory drugs; SIADH, syndrome of inappropriate antidiuretic hormone secretion; SSRIs, selective serotonin reuptake inhibitors; TCAs, tricyclic antidepressants.

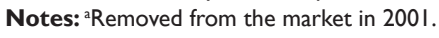


turn included new diagnoses such as depression, Parkinson's disease, cognitive impairment, and incontinence.

In the US, the Beers' criteria have become the most popular and accepted explicit tool used for evaluating PIM prescribing. In fact, many health plans and pharmacy benefit managers have adopted the Beers' criteria or a modification of the list to help identify and target elderly members at risk of ADEs associated with PIM prescribing. Beginning in 2006, the National Committee for Quality Assurance has included a Health Plan Employer Data and Information Set (HEDIS) performance measure for the managed care industry to use to evaluate the percentage of members aged 65 years or older who receive medications that should be avoided. The specifications for this HEDIS performance measure are based on the Beers criteria with some modification. ${ }^{37,38}$

Numerous research studies have employed the Beers' criteria to evaluate PIM prescribing and ADEs in the inpatient setting. Using the most updated Beers' criteria, Gallagher and colleagues found that of the 597 admissions admitted to an Irish university teaching hospital, inappropriate prescribing occurred in $32 \%$ of elderly inpatients in which $24 \%, 6 \%$, and $2 \%$ were taking one, two, or three inappropriate medications, respectively. ${ }^{39}$ Forty-nine percent of patients with inappropriate prescriptions were admitted with ADEs from the inappropriate medication, and $16 \%$ of all admissions were associated with such adverse effects. In a US study, Rothberg found that of 493,971 hospitalized elderly, $49 \%$ received at least one inappropriate prescription and $6 \%$ received three or more. The most common inappropriate medications prescribed consisted of promethazine, diphenhydramine, and propoxyphene. ${ }^{8}$ However, controversy exists regarding exposure to PIMs and ADEs. In a study of 389 elderly inpatients, Page and Ruscin demonstrated that while $27.5 \%$ of inpatients received a drug listed on the Beers' criteria and $32 \%$ did experience an ADE, only 9.2\% of ADEs were attributed to a Beers' criteria medication..$^{40}$ In fact, after controlling for covariates, prescription of a Beers' criteria medication was not significantly associated with experiencing an ADE, discharge to higher levels of care, or in-hospital mortality.

The use of a list of medications, such as the Beers' criteria, as a sole measurement for PIM prescribing has disadvantages. First, the inclusion of some drugs is subject to controversy, and insufficient evidence exists to support inclusion of some drugs presently on the Beers' medication list. Second, the prescription of drugs that should be avoided is a relatively minor problem when compared with other categories of inappropriate prescribing such as underand over-use of medications, drug-drug interactions, drug disease interactions, or drug duplication. The Beers' criteria do not address any of these facets. Third, the reliability of the process to generate such lists is not established. Fourth, while the Beers' criteria may be easy to use, they lack comprehensiveness, organization, and structure.

\section{Improved prescribing in the elderly tool (IPET)}

Referred to as the "Canadian Criteria", the IPET consists of a list of the 14 most prevalent prescription errors identified from a long list of inappropriate prescription instances drawn up by an expert Canadian Consensus Panel in 1997 (Table 3$){ }^{41}$ The IPET was initially validated in a prospective study of acutely hospitalized elderly patients that demonstrated PIM prescribing in $12.5 \%$ of patients..$^{41}$ However, little use of this instrument exists outside of Canada with the exception of one Irish study that found that $22 \%$ of acutely hospitalized elderly were taking at least one inappropriate prescription medication at the point of admission. ${ }^{42}$ Furthermore, as with the Beers' criteria, insufficient convincing evidence exists regarding IPET's efficacy to reduce ADR incidence, reduce excessive health resource utilization or decrease mortality. The IPET only cites 14 instances of inappropriate prescribing, three of which relate solely to TCAs, which are infrequently used in today's medical practice.

Table 3 The improving prescribing in the elderly tool (IPET). Modified with permission from Naugler and colleagues ${ }^{41}$

The following medications represent potentially inappropriate prescriptions in an elderly patient:

$\beta$-blocker and chronic obstructive airways disease

$\beta$-blocker and congestive heart failure

Calcium channel blocker (excluding amlodipine and feldopine) and congestive heart failure

Thiazide diuretic and gout

Long half-life benzodiazepines (chlordiazepoxide, chlorazepate, diazepam, flurazepam, clonazepam, nitrazepam)

Tricyclic antidepressant and glaucoma

Tricyclic antidepressant and heart block

Tricyclic antidepressant with active metabolites (imipramine, doxepin, or amitriptyline)

Methylphenidate for depression

Nonsteroidal anti-inflammatory drugs ${ }^{\mathrm{a}}$ and peptic ulcer disease

Nonsteroidal anti-inflammatory drugs and hypertension

Long term use of nonsteroidal anti-inflammatory drugs for osteoarthritis

Anticholinergic drugs to treat side effects of antipsychotic medications

Long term diphenoxylate to treat diarrhea

Notes: ${ }^{a}$ Consider acetylsalicylic acid as a nonsteroidal anti-inflammatory drug only if the dose is greater than $1300 \mathrm{mg} /$ day. 
Furthermore, the IPET is outdated as it recommends against the use of beta-blockers in heart failure contrary to current guidelines and published evidence. Finally, IPET is heavily weighted towards cardiovascular drug use, psychotropic drug use, and NSAID use and is not organized in any particular order or structure.

\section{Screening tool of older persons (STOPP)}

Developed by a multidisciplinary team of Irish geriatricians, pharmacists, pharmacologists, and primary care physicians, the STOPP incorporates commonly encountered instances of PIM prescribing in older adults that include drug-drug and drug-disease interactions, drugs that adversely affect older patients at risk of falls, and duplicate drug class prescriptions (Table 4). ${ }^{43}$ Its criteria are arranged according to relevant physiological systems for ease of use, and each criterion is accompanied by a concise explanation as to why the prescription is potentially inappropriate. ${ }^{43}$

The performance of the STOPP and Beers criteria has been evaluated for detecting PIM prescribing and related ADRs in 715 older patients admitted a university teaching hospital in Ireland. ${ }^{44}$ The STOPP identified 336 PIMs affecting $35 \%$ of patients, one-third of whom presented with an associated ADE, while the Beers' criteria identified 226 PIMs affecting $25 \%$ of patients, of whom $43 \%$ presented with an associated ADE. The STOPP-related PIMs contributed to $11.5 \%$ of all admissions, while the Beers' criteria-related PIMs contributed to significantly fewer admissions (6\%). The most common PIMs identified by STOPP included use of long-acting benzodiazepines, TCAs with clear-cut

Table 4 STOPP: screening tool of older persons' potentially inappropriate prescriptions $\mathbf{s}^{\mathrm{a}, 43,44}$

\begin{tabular}{|c|c|c|}
\hline System & Drug or drug class & Conditions and concerns (in italics) \\
\hline \multirow[t]{9}{*}{ Cardiovascular } & Aspirin & $\begin{array}{l}\text { - In combination with warfarin without a histamine type } 2 \text { receptor } \\
\text { antagonist (except cimetidine due to warfarin interaction) or PPI } \\
\text { due to high risk of Gl bleeding. } \\
\text { - With a past history of PUD without a histamine } 2 \text { receptor antago- } \\
\text { nist due to risk of bleeding. } \\
\text { - In doses exceeding } 150 \mathrm{mg} / \text { day due to increased bleeding risk and } \\
\text { lack of evidence for increased efficacy. } \\
\text { - With no history of coronary, cerebral, or peripheral vascular symp- } \\
\text { toms or occlusive event as aspirin is not indicated. } \\
\text { - To treat dizziness not clearly attributable to cerebrovascular disease } \\
\text { as aspirin is not indicated. }\end{array}$ \\
\hline & $\beta$-blockers & $\begin{array}{l}\text { - With COPD due to risk of increased bronchospasm. } \\
\text { - In combination with verapamil due to increased risk of symptomatic } \\
\text { heart block. }\end{array}$ \\
\hline & Calcium channel blockers & $\begin{array}{l}\text { - Use of verapamil or diltiazem in patients with NYHA class III or IV } \\
\text { heart failure due to increased risk of toxicity. } \\
\text { - With chronic constipation as this may exacerbated constipation. }\end{array}$ \\
\hline & Clopidogrel & - With concurrent bleeding disorder due to high risk of bleeding. \\
\hline & Digoxin & $\begin{array}{l}\text { - For long term use in doses }>125 \mathrm{mcg} / \text { day with impaired renal func- } \\
\text { tion (GFR }<50 \mathrm{ml} / \mathrm{min} \text { ) due to increased risk of toxicity. }\end{array}$ \\
\hline & Dipyridamole & $\begin{array}{l}\text { - As monotherapy for cardiovascular secondary prevention due to } \\
\text { lack of evidence. } \\
\text { - With concurrent bleeding disorder due to high risk of bleeding. }\end{array}$ \\
\hline & Loop diuretics & $\begin{array}{l}\text { - For dependent ankle edema only (ie, no clinical signs of heart } \\
\text { failure) due to lack of evidence and compression hosiery usually more } \\
\text { appropriate. }\end{array}$ \\
\hline & Thiazide diuretics & - With a history of gout as this may exacerbate gout. \\
\hline & Warfarin & $\begin{array}{l}\text { - In combination with aspirin without a histamine type } 2 \text { receptor } \\
\text { antagonist (except cimetidine due to warfarin interaction) or PPI } \\
\text { due to high risk of Gl bleeding. } \\
\text { - For I st uncomplicated pulmonary embolism for longer than } \\
\text { I2 months duration due to lack of proven benefit. } \\
\text { - With concurrent bleeding disorder due to high risk of bleeding. }\end{array}$ \\
\hline
\end{tabular}

(Continued) 
Table 4 (Continued)

\begin{tabular}{|c|c|c|}
\hline System & Drug or drug class & Conditions and concerns (in italics) \\
\hline \multirow[t]{8}{*}{$\overline{\mathrm{CNS}}$} & Anticholinergics & $\begin{array}{l}\text { - To treat extra-pyramidal side effects of neuroleptic medications due } \\
\text { to risk of anticholinergic toxicity. }\end{array}$ \\
\hline & $\begin{array}{l}\text { Antihistamines (first generation): } \\
\text { diphenydramine, chlorpheniramine, } \\
\text { cyclizine, promethazine }\end{array}$ & $\begin{array}{l}\text { - Prolonged use ( }>\text { I week) due to risk of sedation and anticholinergic } \\
\text { side effects. }\end{array}$ \\
\hline & $\begin{array}{l}\text { Benzodiazepines (long-acting): } \\
\text { chlordiazepoxide, fluazepam, nitrazepam, } \\
\text { chlorazepate }\end{array}$ & $\begin{array}{l}\text { - Avoid due to high risk of prolonged sedation, confusion, impaired } \\
\text { balance, and falls. }\end{array}$ \\
\hline & $\begin{array}{l}\text { Benzodiazepines (with long metabolites): } \\
\text { dizaepam }\end{array}$ & $\begin{array}{l}\text { - Avoid due to high risk of prolonged sedation, confusion, impaired } \\
\text { balance, and falls. }\end{array}$ \\
\hline & Neuroleptics & $\begin{array}{l}\text { - With long term use of }>\text { I month due to high risk of confusion, hypo- } \\
\text { tension, extra-pyramidal side effects, and falls. } \\
\text { - With long term use of }>\text { I month in patients with Parkinson's } \\
\text { disease due to risk worsening, extra-pyramidal symptoms. }\end{array}$ \\
\hline & Phenothiazines & - In patients with epilepsy as phenothiazines may lower seizure threshold. \\
\hline & SSRIs & $\begin{array}{l}\text { - With a history of clinically significant hyponatremia defined as noni- } \\
\text { atrogenic sodium }<130 \text { meq/L within the previous two months. }\end{array}$ \\
\hline & TCAs & $\begin{array}{l}\text { - With dementia due to risk of worsening cognitive impairment. } \\
\text { - With glaucoma as TCAs may exacerbate glaucoma. } \\
\text { - With cardiac conduction abnormalities due to TCAs' pro-arrhythmic } \\
\text { effects. } \\
\text { - With constipation as TCAs may worsen constipation. } \\
\text { - With opiate or calcium channel blockers as TCAs may worsen } \\
\text { constipation. } \\
\text { - With prostatism or prior history of urinary retention due to } \\
\text { increased risk of urinary retention. }\end{array}$ \\
\hline \multirow[t]{4}{*}{ GI } & Anticholinergic antispasmodic drugs & - With chronic constipation due to risk of constipation exacerbation. \\
\hline & $\begin{array}{l}\text { Diphenoxylate, loperamide, or codeine } \\
\text { phosphate }\end{array}$ & $\begin{array}{l}\text { - For treatment of diarrhea of unknown cause due to risk of delayed } \\
\text { diagnosis, possible exacerbation of constipation with overflow diarrhea, } \\
\text { precipitation of toxic megacolon in inflammatory bowel disease, and } \\
\text { delayed recovery in unrecognized gastroenteritis. } \\
\text { - For treatment of severe infective gastroenteritis (ie, bloody diar- } \\
\text { rhea, high fever or severe systemic toxicity) due to risk of exacerba- } \\
\text { tion or protraction of infection. }\end{array}$ \\
\hline & Prochlorperazine, metoclopramide & - With Parkinsonism due to risk of exacerbating Parkinsonism. \\
\hline & PPls & - For PUD at full therapeutic dosage for $>8$ weeks. \\
\hline \multirow[t]{3}{*}{ Respiratory } & Corticosteroids (systemic) & $\begin{array}{l}\text { - For maintenance therapy in moderate to severe COPD instead of } \\
\text { inhaled corticosteroids due to unnecessary exposure to long-term side } \\
\text { effects of systemic steroids. }\end{array}$ \\
\hline & Ipratropium (nebulized) & - In patients with glaucoma due to possible glaucoma exacerbation. \\
\hline & Theophylline & $\begin{array}{l}\text { - As monotherapy for COPD as more safer, more effective alternatives } \\
\text { exist and the risk of adverse effects due to narrow therapeutic index. }\end{array}$ \\
\hline Musculoskeletal & NSAIDs & $\begin{array}{l}\text { - With a history of PUD or GI bleeding, unless with concurrent } \\
\text { histamine type } 2 \text { receptor blocker, PPI or misoprostol due to risk of } \\
\text { PUD relapse. } \\
\text { - With moderate ( } 160 / 100-179 / 109 \mathrm{mmHg} \text { ) or severe } \\
(>180 / 110 \mathrm{mmHg} \text { ) hypertension due to risk of exacerbation of } \\
\text { hypertension. } \\
\text { - With heart failure due to risk of heart failure exacerbation. } \\
\text { - With warfarin concomitantly due to risk of GI bleeding. } \\
\text { - With chronic renal failure (GFR } 20-50 \mathrm{ml} / \mathrm{min}) \text { due to risk of dete- } \\
\text { rioration in renal function. } \\
\text { - With long-term use ( }>3 \text { months) for relief of mild joint pain in } \\
\text { osteoarthritis as simple analgesics preferable and usually as effective } \\
\text { for pain relief. }\end{array}$ \\
\hline
\end{tabular}


Table 4 (Continued)

\begin{tabular}{|c|c|c|}
\hline System & Drug or drug class & Conditions and concerns (in italics) \\
\hline & Colchicine & $\begin{array}{l}\text { - For chronic treatment of gout where there is no contraindication } \\
\text { to allopurinol as allopurinol is considered first choice for prophylaxis in } \\
\text { gout. }\end{array}$ \\
\hline & Corticosteroids & $\begin{array}{l}\text { - For chronic treatment of gout where there is no contraindication } \\
\text { to allopurinol as allopurinol is considered first choice for prophylaxis in } \\
\text { gout. } \\
\text { - As long-term ( }>3 \text { months) monotherapy for rheumatoid arthritis } \\
\text { or osteoarthritis due to risk of major systemic corticosteroid } \\
\text { side-effects. }\end{array}$ \\
\hline \multirow[t]{2}{*}{ Urogenital } & Antimuscarinic drugs & $\begin{array}{l}\text { - With dementia due to risk of increased confusion and agitation. } \\
\text { - With chronic glaucoma due to risk of acute exacerbation of glaucoma. } \\
\text { - With chronic constipation due to risk of exacerbation of constipation. } \\
\text { - With chronic prostatism due to risk of urinary retention. }\end{array}$ \\
\hline & $\alpha$-blockers & $\begin{array}{l}\text { - In males with frequent incontinence (ie, one or more episodes of } \\
\text { incontinence daily) due to risk of urinary frequency and worsening } \\
\text { incontinence. } \\
\text { - With long term urinary catheter in situ (ie, more than two months) } \\
\text { as drug is not indicated. }\end{array}$ \\
\hline \multirow[t]{3}{*}{ Endocrine } & Chlorpropamide or glibenclamide & - With type 2 diabetes due to risk of prolonged hypoglycemia. \\
\hline & $\beta$-blockers & $\begin{array}{l}\text { - In those with diabetes mellitus and frequent hypoglycemic episodes } \\
\text { (ie, } \geq \text { I episodes/month) due to risk of masking hypoglycemic symp- } \\
\text { toms. }\end{array}$ \\
\hline & Estrogen & $\begin{array}{l}\text { - With a history of breast cancer or VTE due to increased risk of } \\
\text { recurrence. } \\
\text { - Without progestogen in patients with intact uterus due to risk of } \\
\text { endometrial cancer. }\end{array}$ \\
\hline \multicolumn{3}{|l|}{ Drug issues } \\
\hline Analgesic drugs & Opiates & $\begin{array}{l}\text { - Use of long-term power opiates (eg, morphine or fentanyl) as first } \\
\text { line therapy for mild-moderate pain as WHO analgesic ladder is not } \\
\text { observed. } \\
\text { - Regular use for more than two weeks in those with chronic consti- } \\
\text { pation without use of laxitatives due to risk of severe constipation. } \\
\text { - Long-term use in those with dementia unless indicated for palliative } \\
\text { care or management of moderate-severe chronic pain syndrome } \\
\text { due to risk of exacerbation of cognitive impairment. }\end{array}$ \\
\hline \multirow[t]{5}{*}{ Duplicate drug class } & ACE inhibitors & - Use of any two concurrent duplicate medications as optimization \\
\hline & Loop diuretics & of monotherapy within a single drug class should be observed prior to \\
\hline & NSAIDs & considering a new drug class. \\
\hline & Opiates & \\
\hline & SSRIs & \\
\hline \multirow{5}{*}{$\begin{array}{l}\text { Drugs adversely affecting } \\
\text { those prone to falls }{ }^{\mathrm{b}}\end{array}$} & Antihistamines (first generation) & - May cause sedation and impair sensorium. \\
\hline & Benzodiazepines & - May cause sedation and impair sensorium. \\
\hline & Neuroleptic drugs & - May cause gait dyspraxia and Parkinsonism. \\
\hline & Opiates & $\begin{array}{l}\text { - Long-term use in those with recurrent falls due to risk of drowsiness, } \\
\text { postural hypotension, and vertigo. }\end{array}$ \\
\hline & Vasodilators (known to cause hypotension) & $\begin{array}{l}\text { - In those with persistent postural hypotension } \\
\text { (ie, recurrent }>20 \mathrm{mmHg} \text { drop in systolic blood pressure) due to } \\
\text { risk of syncope and falls. }\end{array}$ \\
\hline
\end{tabular}

Abbreviations: ACE, angiotensin-converting enzyme; CNS, central nervous system; COPD, chronic obstructive pulmonary disease; GI, gastrointestinal; NYHA, New York Heart Association; NSAIDs, nonsteroidal anti-inflammatory drugs; PPIs, proton pump inhibitors; PUD, peptic ulcer disease; SSRIs, selective serotonin re-uptake inhibitors; TCAs, tricyclic antidepressants; $\mathrm{VTE}$, venous thromboembolism;WHO,World Health Organization.

Notes: ${ }^{2}$ The following prescription drugs are potentially inappropriate in persons ages $\geq 65$ years of age; ${ }^{b} \geq \mathbf{l}$ fall in the past three months. 
contraindications, first generation antihistamines, vasodilator drugs known to cause hypotension in patients with persistent postural hypotension, inappropriate use of NSAIDs and opiates, and duplicate drug class prescriptions such as two angiotensin converting enzyme inhibitors, two NSAIDs, two selective serotonin reuptake inhibitors or dual antiplatelet therapy without indication. The authors concluded that compared to the Beers' criteria the STOPP criteria are more sensitive in identifying patients liable to suffer harm from an ADE because of PIM prescribing.

The advantages of the STOPP consist of good interrater reliability, inclusion of both American and European medications, organization and structure based physiological systems, and short time to complete ( $\sim 3$ minutes). However, this European tool needs to be evaluated in additional studies and in other settings.

\section{Medication appropriateness index (MAI)}

Initially developed by Dr Joseph Hanlon and colleagues, the MAI is a validated measure of prescribing appropriateness that assesses ten elements of prescribing: indication, effectiveness, dose, correct directions, practical directions, drug-drug interactions, drug-disease interactions, duplication, duration, and cost. ${ }^{45}$ While this implicit approach requires clinical judgment to assess criteria, the index has operational definitions and explicit instructions, which standardize the rating process. The ratings generate a weighted score that serves as a summary measure of prescribing appropriateness ranging from 0 to $18(0=$ no item inappropriate; $18=$ all items inappropriate). Three components of the MAI (indication, effectiveness, and duplication) can be used to detect unnecessary polypharmacy and PIM prescribing. ${ }^{17,46}$

In an evaluation of 11 Veterans Affairs Medical Centers involving 397 frail elderly inpatients, Hanlon and colleagues found that $92 \%$ of subjects had at least one drug with one or more inappropriate ratings. The most common problems involved expensive drugs (70\%), impractical directions (55.2\%), and incorrect dosages (50.9\%). ${ }^{6}$ The most prevalent medication classes with appropriateness concerns consisted of gastric $(50.6 \%)$, cardiovascular $(47.6 \%)$, and central nervous system $(23.9 \%)$ agents. In a similar inpatient population, Hajjar and colleagues found that $44 \%$ of frail elderly inpatients had at least one unnecessary medication at discharge. ${ }^{17}$ From their analysis, the factors most commonly associated with unnecessary drug prescribing consisted of hypertension diagnosis, multiple prescribers, and nine or more medications.

The MAI as a tool to evaluate PIM prescribing has major advantages: it has been tested in both the inpatient and ambulatory settings, exhibits excellent intra-rater and inter-rater reliability, and has face and content validity. It addresses multiple components of prescribing appropriateness, and can be applied to every medication in the context of patient-specific characteristics. However, the tool is more time-consuming to complete ( $\sim 10$ minutes per drug assessed) and does not assess under-prescribing (untreated indications). ${ }^{46}$ Most studies using the MAI have been performed in a single setting, with groups of elderly veterans from the Veterans Affairs Medical Center in Durham, North Carolina. As with other tools developed to date, the index needs to be validated in other populations and settings before being used universally.

\section{Strategic approaches to curtailing PIM prescribing}

Conceptually, PIM prescribing in the inpatient setting is a multi-faceted function of the patient, prescriber, and environment. First, the clinical needs of the patient must be the primary determinant of prescribing decisions. Appropriate prescribing should aim to promote the use of evidence-based therapies while minimizing the use of medications for which there is no clinical need, questionable evidence, or duplication. The patient's perceptions and preferences should also be considered. Second, prescribing is done mainly by providers who use their own clinical experience and attitudes in making medication decisions. Factors that contribute to PIM prescribing include inadequate training in geriatric pharmacotherapy as well as the absence of communication between providers practicing in different settings, or between specialists and the primary care provider. Finally, the environment in which the prescriber operates can affect prescribing decisions. Unfortunately, the acute care setting does not encourage review of chronic and preventive medications. Furthermore, the inpatient environment may lack the technological infrastructure to share information relating to drugs during transitions of care, which ultimately compromises quality.

With this in mind, several strategic approaches exist to potentially minimize PIM prescribing. The question surrounding which tool to use to measure quality of prescribing remains controversial. Quality measures are often chosen not only because of the clinical importance of the construct they measure but also their ease of use. In particular, drugs-toavoid criteria have been a popular tool for research, in part due to their easy applicability to administrative databases. Although easy-to-administer measures such as drugs-toavoid criteria (eg, Beers' criteria) capture useful elements of prescribing quality, that the relative ease of these metrics 
creates an immediate danger that they will drive quality assessment and improvements efforts rather than vice versa. In fact, significant discordance exists between the MAI and Beers' criteria when using these tools to evaluate drug prescribing quality in similar populations. ${ }^{47}$ Furthermore, when prescribing, one must take into account the patient as a whole, including his or her life expectancy and quality of life within a social and economical environment, select essential medications, and avoid drugs with a poorer benefit-to-risk ratio. Unfortunately, explicit prescribing criteria may force the prescriber to ignore these considerations by prescribing at the bedside according to inflexible, rigid guidelines. Therefore, based on these observations, because using a single tool may fail to capture the overall quality of a patient's medication regimen, it would seem prudent to consider employing multiple tools and multifaceted perspectives to capture the range of quality problems that may be present in medication prescribing.

While primarily documented in the ambulatory setting, additional strategies for hospital settings consist of using a computerized decision support system, implementing didactic educational programs within the health system, utilizing clinical pharmacist expertise on clinical rounds or for prospective medication review, and considering a comprehensive geriatric evaluation and management (GEM) care approach. ${ }^{5,48-56}$ This latter approach consists of a multidisciplinary team, which may include a geriatrician and other health care providers with specialized geriatric training (eg, nurses, pharmacists, dieticians, social workers, and psychologists). Data from the inpatient setting suggest that employing a GEM care team can lower potential drug-drug interactions and the number of unnecessarily prescribed drugs from admission to discharge, as well as decrease the time to discharge.$^{5,52-54}$ Finally, infrastructure and hospital policies to provide medication reconciliation on admission and at discharge are crucial in response to medication discrepancies within the inpatient setting documented as problematic. Coleman and colleagues found that $14 \%$ of older community-dwelling patients experienced post-hospital medication discrepancies within two weeks of discharge, and that half of those discrepancies were systemrelated. ${ }^{16}$ Presently, medication reconciliation is included in the Joint Commission's National Patient Safety Goals. Goal 8 states that hospitals must "accurately and completely reconcile patient medications across the continuum of care." 57 In order to prevent fragmentation of care from the inpatient to the outpatient setting, clinical pharmacists and nurses have served as potential medication transition coordinators and discharge advocates. Data from two studies suggest that such an approach can lower the rate of hospital readmission and emergency department visits. ${ }^{50,58}$

\section{Summary and future concerns}

The prescribing of medications is a fundamental component of the care of the elderly, and the optimization of drug prescribing has become an important public health concern. The inpatient setting can be particularly hazardous regarding ADEs due to the problem of multiple prescribers, medication reconciliation issues, and poor communication between outpatient and inpatient providers. While tools are available to identify PIM prescribing and potential strategies exist to curtail the problem, several fundamental issues still exist. First, from an interventional and health care research perspective, even though data provide useful insights into the effectiveness of different approaches, the effect on important health outcomes and health care costs still needs to be evaluated. Second, despite substantial resource dedication to developing and testing the effectiveness of interventions to improve prescribing, widespread diffusion of successful methods has not yet been achieved. It also seems that our current culture, from the perspective of patients and prescribers, relies too heavily on pharmacological interventions to address medical problems. The use of medications is often the first and only intervention sought, when other proven interventions, such as psychotherapy for behavioral and mental health issues, may be appropriate. Also, to fully address appropriateness of prescribing, not only should the use of inappropriate medications be avoided, but the use of indicated and beneficial medications should be encouraged. In this instance, evidence-based criteria, such as the START (Screening Tool to Alert doctors to Right Treatment) criteria should compliment assessments. ${ }^{59}$ Finally, the responsibility of appropriate prescribing should no longer fall solely on the shoulders of physician prescriber. Rather the responsibility should be shared across the multidisciplinary continuum of care with all health care professionals who provide care for the older adult.

\section{Disclosures}

The authors report no conflicts of interest in this work.

\section{References}

1. Institute of Medicine. To Err Is Human: Building A Safer Health System. Washington, DC: National Academies Press; 1999.

2. Gallagher P, Barry P, O’Mahony D. Inappropriate prescribing in the elderly. J Clin Pharm Ther. 2007;32(2):113-121.

3. Laroche ML, Charmes JP, Nouaille Y, et al. Is inappropriate medication use a major cause of adverse drug reactions in the elderly? Br J Clin Pharmacol. 2007;63(2):177-186. 
4. Qato DM, Alexander GC, Conti RM, et al. Use of prescription and over-the-counter medications and dietary supplements among older adults in the United States. JAMA. 2008;300(24):2867-2878.

5. Spinewine A, Schmader KE, Barber N, et al. Appropriate prescribing in elderly people: how well can it be measured and optimised? Lancet. 2007;370(9582):173-184.

6. Hanlon JT, Artz MB, Pieper CF, et al. Inappropriate medication use among frail elderly inpatients. Ann Pharmacother. 2004;38(1):9-14.

7. Onder G, Landi F, Cesari M, et al. Inappropriate medication use among hospitalized older adults in Italy: results from the Italian Group of Pharmacoepidemiology in the Elderly. Eur J Clin Pharmacol. 2003;59(2):157-162.

8. Rothberg MB, Pekow PS, Liu F, et al. Potentially inappropriate medication use in hospitalized elders. J Hosp Med. 2008;3(2):91-102.

9. Agency for Health care Research and Quality. HCUP Facts and Figures, 2006: Statistics on Hospital-based Care in the United States. Available from: http://www.hcup-us.ahrq.gov/reports/factsandfigures/HAR_2006. pdf. Accessed December 14, 2009.

10. Edwards RF, Harrison TM, Davis SM. Potentially inappropriate medication use amoung frail elderly inpatients. Consult Pharmacist. 2003;18(1):37-42.

11. Jencks SF, Williams MV, Coleman EA. Rehospitalizations among patients in the Medicare fee-for-service program. $N$ Engl J Med. 2009;360(14):1418-1428

12. Creditor MC. Hazards of hospitalization of the elderly. Ann Intern Med. 1993;118(3):219-223.

13. Friedman SM, Mendelson DA, Bingham KW, McCann RM. Hazards of hospitalization: residence prior to admission predicts outcomes. Gerontologist. 2008;48(4):537-541.

14. Gandhi TK, Weingart SN, Borus J, et al. Adverse drug events in ambulatory care. $N$ Engl J Med. 2003;348(16):1556-1564.

15. Lazarou J, Pomeranz BH, Corey PN. Incidence of adverse drug reactions in hospitalized patients: a meta-analysis of prospective studies. JAMA. 1998;279(15):1200-1205.

16. Coleman EA, Smith JD, Raha D, Min SJ. Posthospital medication discrepancies: prevalence and contributing factors. Arch Intern Med. 2005;165(16):1842-1847.

17. Hajjar ER, Hanlon JT, Sloane RJ, et al. Unnecessary drug use in frail older people at hospital discharge. J Am Geriatr Soc. 2005;53(9): 1518-1523.

18. Bates DW, Miller EB, Cullen DJ, et al. Patient risk factors for adverse drug events in hospitalized patients. ADE Prevention Study Group. Arch Intern Med. 1999;159(21):2553-2560.

19. Carey IM, De Wilde S, Harris T, et al. What factors predict potentially inappropriate primary care prescribing in older people? Analysis of UK primary care patient record database. Drugs Aging. 2008;25(8): 693-706.

20. Evans RS, Lloyd JF, Stoddard GJ, et al. Risk factors for adverse drug events: a 10-year analysis. Ann Pharmacother. 2005;39(7-8): 1161-1168.

21. Kanjanarat P, Winterstein AG, Johns TE, et al. Nature of preventable adverse drug events in hospitals: a literature review. Am J Health Syst Pharm. 2003;60(17):1750-1759.

22. Turnheim K. When drug therapy gets old: pharmacokinetics and pharmacodynamics in the elderly. Exp Gerontol. 2003;38(8):843-853.

23. Kinirons MT, Crome P. Clinical pharmacokinetic considerations in the elderly. An update. Clin Pharmacokinet. 1997;33(4):302-312.

24. El Desoky ES. Pharmacokinetic-pharmacodynamic crisis in the elderly. Am J Ther. 2007;14(5):488-498.

25. Hajjar ER, Cafiero AC, Hanlon JT. Polypharmacy in elderly patients. Am J Geriatr Pharmacother. 2007;5(4):314-316.

26. Goldberg RM, Mabee J, Chan L, Wong S. Drug-drug and drug-disease interactions in the ED: analysis of a high-risk population. Am J Emerg Med. 1996;14(5):447-450.

27. Col N, Fanale JE, Kronholm P. The role of medication noncompliance and adverse drug reactions in hospitalizations of the elderly. Arch Intern Med. 1990;150(4):841-845.
28. Ray WA, Chung CP, Murray KT, et al. Atypical antipsychotic drugs and the risk of sudden cardiac death. N Engl J Med. 2009;360(3):225-235.

29. Gill SS, Bronskill SE, Normand SL, et al. Antipsychotic drug use and mortality in older adults with dementia. Ann Intern Med. 2007;146(11):775-786.

30. Rochon PA, Normand SL, Gomes T, et al. Antipsychotic therapy and short-term serious events in older adults with dementia. Arch Intern Med. 2008;168(10):1090-1096.

31. Robert Wood Johnson Foundation. Partnership For Solutions, Better Living for People with Chronic Conditions [homepage on the internet]. Disease management and multiple chronic conditions. 2006. Availability from www.partnershipforsolutions.org/DMS/files/DMfactsheet21final. pdf. Accessed December 14, 2009.

32. Merrill CT, Elixhauser A. Hospitalization in the United States. HCUP Fact Book No. 6. Rockville (MD): Agency for Health care Research and Quality; 2002.

33. Page RL 2nd, Strongin K, Millis R, et al. Medicare beneficiaries with mild to moderate heart failure see 15-23 different providers annually (Abstract \#5922). Circulation. 2007;118(18 ):S1030.

34. Beers MH, Ouslander JG, Rollingher I, et al. Explicit criteria for determining inappropriate medication use in nursing home residents. UCLA Division of Geriatric Medicine. Arch Intern Med. 1991;151(9): 1825-1832.

35. Beers MH. Explicit criteria for determining potentially inappropriate medication use by the elderly. An update. Arch Intern Med. 1997;157(14):1531-1536.

36. Fick DM, Cooper JW, Wade WE, et al. Updating the Beers criteria for potentially inappropriate medication use in older adults: results of a US consensus panel of experts. Arch Intern Med. 2003;163(22): 2716-2724.

37. National Committee for Quality Assurance (NCQA). HEDIS ${ }^{\circledR} 2006$ Technical Specifications. Item \#10284-100-06. Washington, DC, 2005.

38. National Committee for Quality Assurance (NCQA). HEDIS ${ }^{\circledR} 2007$ Technical Specifications. Item \#10284-100-06. Washington, DC, 2006.

39. Gallagher PF, Barry PJ, Ryan C, et al. Inappropriate prescribing in an acutely ill population of elderly patients as determined by Beers' Criteria. Age Ageing. 2008;37(1):96-101.

40. Page RL 2nd, Ruscin JM. The risk of adverse drug events and hospital-related morbidity and mortality among older adults with potentially inappropriate medication use. Am J Geriatr Pharmacother. 2006;4(4):297-305.

41. Naugler CT, Brymer C, Stolee P, Arcese ZA. Development and validation of an improving prescribing in the elderly tool. Can J Clin Pharmacol. 2000;7(2):103-107.

42. Barry PJ, O'Keefe N, O'Connor KA, O'Mahony D. Inappropriate prescribing in the elderly: a comparison of the Beers criteria and the improved prescribing in the elderly tool (IPET) in acutely ill elderly hospitalized patients. J Clin Pharm Ther. 2006;31(6):617-626.

43. Gallagher P, Ryan C, Byrne S, et al. STOPP (Screening Tool of Older Person's Prescriptions) and START (Screening Tool to Alert doctors to Right Treatment). Consensus validation. Int J Clin Pharmacol Ther. 2008;46(2):72-83.

44. Gallagher P, O’Mahony D. STOPP (Screening Tool of Older Persons' potentially inappropriate Prescriptions): application to acutely ill elderly patients and comparison with Beers' criteria. Age Ageing. 2008;37(6):673-679.

45. Hanlon JT, Schmader KE, Samsa GP, et al. A method for assessing drug therapy appropriateness. J Clin Epidemiol. 1992;45(10):1045-1051.

46. Samsa GP, Hanlon JT, Schmader KE, et al. A summated score for the medication appropriateness index: development and assessment of clinimetric properties including content validity. J Clin Epidemiol. 1994;47(8):891-896.

47. Steinman MA, Rosenthal GE, Landefeld CS, et al. Conflicts and concordance between measures of medication prescribing quality. Med Care. 2007;45(1):95-99. 
48. Agostini JV, Concato J, Inouye SK. Improving sedative-hypnotic prescribing in older hospitalized patients: provider-perceived benefits and barriers of a computer-based reminder. J Gen Intern Med. 2008;23 Suppl 1:32-36.

49. Brekke M, Rognstad S, Straand J, et al. Pharmacologically inappropriate prescriptions for elderly patients in general practice: How common? Baseline data from The Prescription Peer Academic Detailing (Rx-PAD) study. Scand J Prim Health Care. 2008;26(2):80-85.

50. Crotty M, Rowett D, Spurling L, et al. Does the addition of a pharmacist transition coordinator improve evidence-based medication management and health outcomes in older adults moving from the hospital to a long-term care facility? Results of a randomized, controlled trial. Am J Geriatr Pharmacother. 2004;2(4):257-264.

51. Hanlon JT, Weinberger M, Samsa GP, et al. A randomized, controlled trial of a clinical pharmacist intervention to improve inappropriate prescribing in elderly outpatients with polypharmacy. $\mathrm{Am} \mathrm{J} \mathrm{Med.}$ 1996;100(4):428-437.

52. Saltvedt I, Spigset O, Ruths S, et al. Patterns of drug prescription in a geriatric evaluation and management unit as compared with the general medical wards: a randomised study. Eur J Clin Pharmacol. 2005;61(12):921-928
53. Schmader KE, Hanlon JT, Pieper CF, et al. Effects of geriatric evaluation and management on adverse drug reactions and suboptimal prescribing in the frail elderly. Am J Med. 2004;116(6):394-401.

54. Spinewine A, Swine C, Dhillon S, et al. Effect of a collaborative approach on the quality of prescribing for geriatric inpatients: a randomized, controlled trial. J Am Geriatr Soc. 2007;55(5):658-665.

55. Tamblyn R, Huang A, Perreault R, et al. The medical office of the $21 \mathrm{st}$ century (MOXXI): effectiveness of computerized decision-making support in reducing inappropriate prescribing in primary care. CMAJ. 2003;169(6):549-556.

56. Yourman L, Concato J, Agostini JV. Use of computer decision support interventions to improve medication prescribing in older adults: a systematic review. Am J Geriatr Pharmacother. 2008;6(2):119-129.

57. Young B. Medication reconciliation matters. Medsurg Nurs. 2008;17(5):332-336.

58. Jack BW, Chetty VK, Anthony D, et al. A reengineered hospital discharge program to decrease rehospitalization: a randomized trial. Ann Intern Med. 2009;150(3):178-187.

59. Ryan C, O'Mahony D, Byrne S. Application of STOPP and START criteria: interrater reliability among pharmacists. Ann Pharmacother. 2009;43(7):1239-1244.
Clinical Interventions in Aging

\section{Publish your work in this journal}

Clinical Interventions in Aging is an international, peer-reviewed journal focusing on evidence-based reports on the value or lack thereof of treatments intended to prevent or delay the onset of maladaptive correlates of aging in human beings. This journal is indexed on PubMed Central, MedLine, the American Chemical Society's 'Chemical Abstracts Ser-

\section{Dovepress}

vice' (CAS), Scopus and the Elsevier Bibliographic databases. The manuscript management system is completely online and includes a very quick and fair peer-review system, which is all easy to use. Visit http://www.dovepress.com/testimonials.php to read real quotes from published authors. 